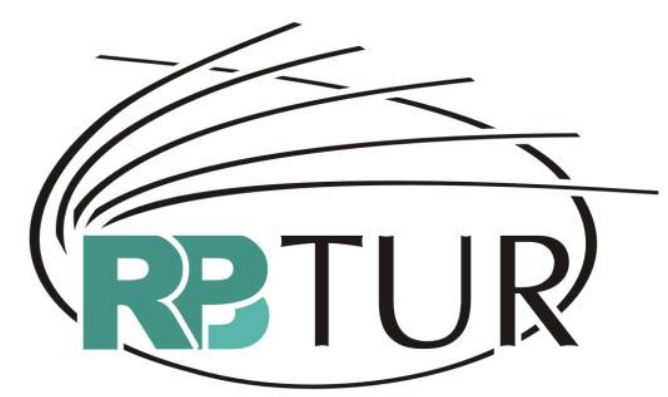

REVISTA BRASILEIRA DE PESQUISA EM TURISMO

\title{
ESPAÇOS DE RESERVA DO CAPITAL NA ORLA OESTE DE FORTALEZA (CEARÁ, BRASIL): DEMANDAS PARA LAZER E TURISMO
}

\author{
SPACES FOR CAPITAL RESERVE AT FORTALEZA (STATE OF \\ CEARÁ, BRAZIL) WEST COAST: DEMANDS FOR LEISURE AND \\ TOURISM
}

\section{ESPACIOS DE RESERVA DEL CAPITAL EN LA COSTA OESTE DE FORTALEZA (ESTADO DE CEARÁ, BRASIL): DEMANDAS PARA RECREACIÓN Y TURISMO}

Luzia Neide Coriolano ${ }^{1}$ Karlos Markes Parente ${ }^{2}$

\begin{abstract}
Resumo: Esta pesquisa investiga as transformações, em função de lazer e turismo, do uso do solo urbano de Fortaleza (Estado de Ceará, Brasil), especificamente da orla oeste, e as políticas de gestão de elementos produtores do espaço, bem como os conflitos de interesses e contradições de esferas públicas e privadas com relação às políticas territoriais. São analisados os modos de apropriação da orla oeste, espaço de reserva do capital, em contraponto à orla leste, que se caracteriza como espaço de turismo globalizado e, visando à modernização tipicamente capitalista, confere grandes transformações à paisagem urbana. Examina-se criticamente o avanço da especulação imobiliária sobre esse espaço de reserva da cidade por meio de enclaves socioespaciais. Realidades socioeconômicas do Resort Marina Park Hotel, considerado nessa pesquisa como enclave de riqueza em área de miséria, e do Arraial Moura Brasil, marginalizado e historicamente conhecido como zona de prostituição, são confrontadas. As políticas públicas e privadas em torno desta problemática são também analisadas.

${ }^{1}$ Doutora em Geografia. Professora do Programa de Pós-Graduação em Geografia (PROPGEO) do Mestrado Profissional em Gestão de Negócios Turísticos e Coordenadora do Laboratório de Estudos do Território e do Turismo (NETTUR) da Universidade Estadual do Ceara (UECE). Email: luzianeidecoriolano@gmail.com

2 Mestrando em Geografia da UECE-MAG, Bolsista do CNPq, pesquisador do Laboratório de Estudos do Território e do Turismo Laboratório de Estudos do Território e do Turismo (NETTUR) da Universidade Estadual do Ceara (UECE). Email: karlosmarkes@hotmail.com
\end{abstract}


ISSN: $1982-6125$

Palavras-chave: Turismo. Espaço. Lazer. Política Pública e Privada. Fortaleza. Brasil.

Abstract: This research aims to understand the changes in urban land use due to leisure and tourism at Fortaleza (Ceará State, Brazil), specifically at the west coast and the management policies for production of spaces agency. The conflicts of interests and contradictions concerning the public and private spheres related to the territorial politics are also investigated. West coast space appropriation manners, as capital space reserve, were analyzed in contrast to the east border, which is described as an area for global tourism that, striving for a typical capitalist upgrade, presents great changes on the urban landscape. The progress of real estate speculation on the city's reserve areas through socio-spatial enclaves is also critically examined. So, the socioeconomic realities of the Marina Park Resort Hotel, which is considered in this research as a sort of enclave of wealth inside an area of poverty, and Arraial Moura Brazil, the historically marginalized area known as a prostitution district, will be compared. Public policy in these matters will also be assessed.

Keywords: Tourism. Space. Leisure. Public and Privet Policy Tourism. Fortaleza. Brazil.

Resumen: Esta investigación se refiera a las transformaciones en el uso del suelo, en función de la recreación y el turismo, en la costa oeste de la ciudad de Fortaleza (Estado de Ceará, Brasil) y a las políticas de gestión de los elementos productores del espacio, así como los conflictos, intereses y contradicciones de las esferas pública y privada en relación a las políticas territoriales. Se analizan las formas de apropiación de la costa oeste, espacio de reserva de capital, en contrapunto con la costa este, que se caracteriza como un espacio de turismo globalizado, que en ós de una modernización típicamente capitalista provoca grandes transformaciones en el paisaje urbano. Se examina críticamente el avance de la especulación inmobiliaria sobre este espacio de reserva de la ciudad, por medio de enclaves socio-espaciales. Son confrontadas las realidades socio económicas del Resort Marina Park Hotel, considerado en esta investigación un enclave de riqueza en área de miseria y la del barrio Arraial Moura Brasil, marginalizado e históricamente conocido como zona de prostitución. También se analizan las políticas públicas y privadas sobre los problemas tratados.

Palabras clave: Turismo. Espacio. Ocio. Políticas Públicas y Privadas. Fortaleza. Brasil.

\section{Considerações Iniciais}

Esta pesquisa trata de espaços públicos e privados de lazer e turismo na orla de Fortaleza, com ênfase no litoral oeste, por considerá-lo espaço de reserva do capital, tradicionalmente pouco visado pelos governos e empresários do lazer e turismo, nos últimos anos, em disputa do mercado imobiliário. É cotado como espaço de expansão de aparatos urbanos, de lazer e turísticos, com propostas intervencionistas de governos a exemplo do Projeto Costa Oeste de 1995-1998 e do Projeto Vila do Mar de 2008. 
Historicamente a orla oeste de Fortaleza foi ocupada, em grande parte, por favelas, equipamentos públicos de segunda ordem e indústrias. Contraditoriamente, ao lado de paisagens naturais de relevante beleza cênica, surgem favelas e antigas indústrias, passa pelo reordenamento urbano, visada por empreendedores do turismo globalizado, ou de mega empreendimentos e resorts. Espaços urbanos ficam em reserva para posterior incorporação ao reordenamento espacial.

Nitidamente há fortes embates entre interessados na apropriação do espaço: moradores - de favela ou da classe média; empresários do turismo, indústria e especuladores imobiliários; e Estado em esferas municipal e estadual. O território do turismo globalizado expande-se cada vez mais em direção à área ocupada por famílias de trabalhadores ameaçados de remoção. A segregação socioespacial nesse trecho da orla associa-se à pobreza, insegurança e limita acesso ao lazer do fortalezense, é que as luzes da beira mar se escondem. Assim, propostas e planos governamentais são de reordenar, modernizar e redirecionar a área para o turismo, o que implica sacrifício de moradores tradicionais e desprestígio de famílias com raízes no lugar em nome do desenvolvimento urbano, econômico e turístico.

Os conflitos suscitam reflexões acerca de pretensas dualidades de produção desigual do espaço, levando à crença em duas orlas, quando, na verdade, tem-se totalidade urbana. Os questionamentos buscam compreensão de conflitos do processo de reestruturação da cidade e de cooptação da orla oeste pelo capital.

$\mathrm{Na}$ figura 1 vê-se a orla oeste de Fortaleza, demarcado o espaço apropriado pelo turismo globalizado, com favelas, em destaque o Arraial Moura Brasil e a Pirambu, considerada a segunda maior favela da América Latina. 
ISSN: $1982-6125$

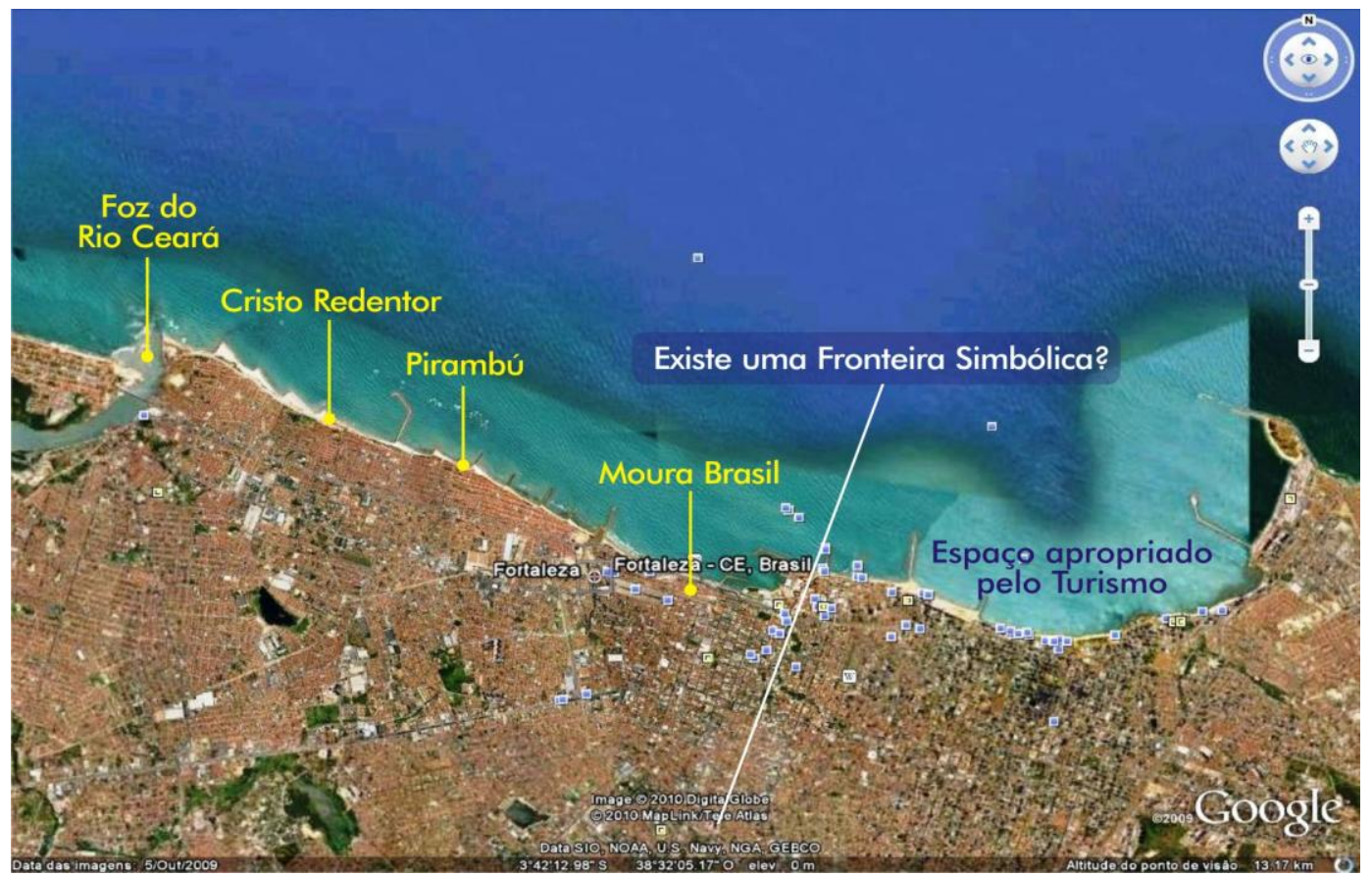

Figura 1 - Orla oeste de Fortaleza

Fonte: Google Earth 2010

O recorte espacial (figura 1) vai da foz do Rio Ceará, na Praia das Goiabeiras, passa pelo Bairro Barra do Ceará e por toda extensão da Av. Presidente Castelo Branco (Av. Leste-Oeste) para chegar ao Moura Brasil, com ocupação irregular e predomínio de favelas. Do centro da cidade e da Praia de Iracema ao Porto do Mucuripe, a orla é de riqueza, conforto e luxo. É a vitrine do turismo de sol e praia de Fortaleza, onde se erguem hotéis de bandeira internacional, flats, restaurantes, bancos, casas de shows e oferta de qualidade de serviços urbanos e turísticos.

Nas figuras 2 e 3 vêem-se as contradições com o Mucuripe, ostentando hotéis internacionais, flats e restaurantes; e a Avenida Leste-Oeste, favelas e equipamentos como o Instituto Médico Legal e Estação de Tratamento de Esgoto da Cagece. 
ISSN: $1982-6125$

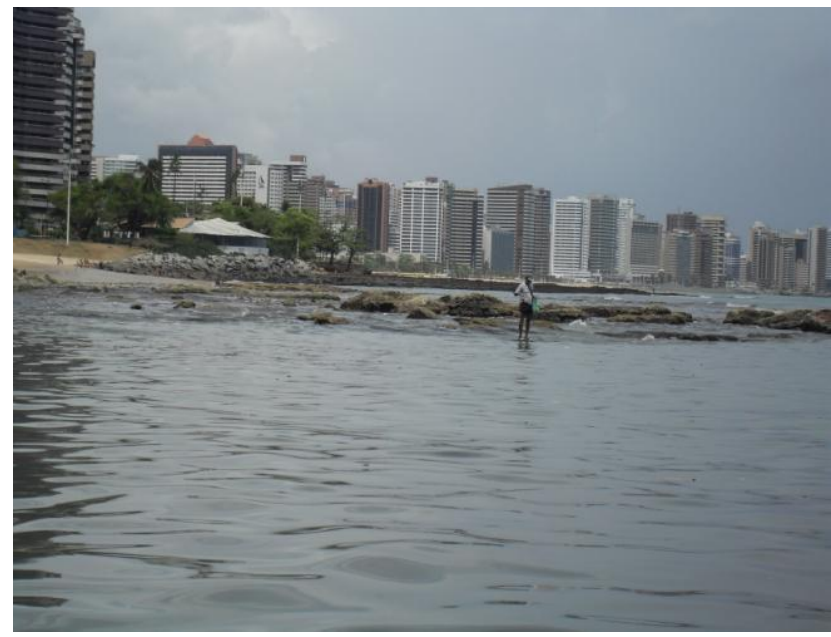

Figura 2 - Praia do Mucuripe

Fonte: Thayná C. Marques (LAGIZC)

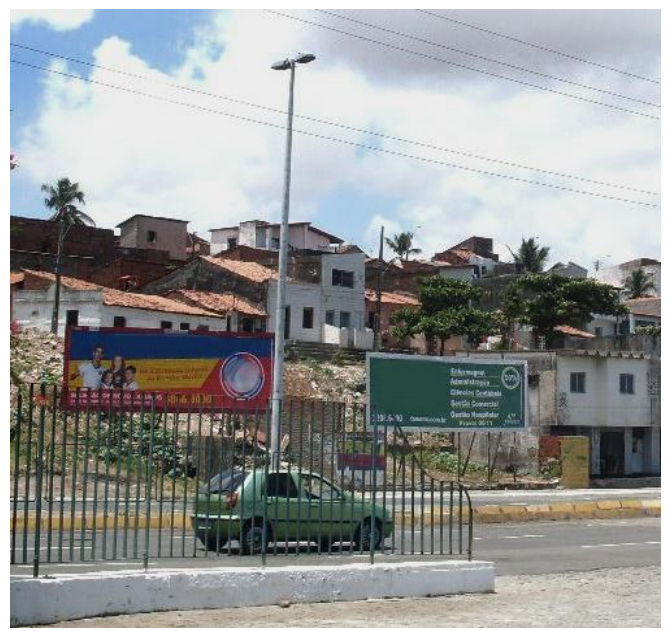

Figura 3 - Av. Leste-Oeste - Arraial Moura Brasil Fonte: NETTUR

\section{Fortaleza: Metrópole Sertaneja Banhada Pelo Mar}

Fortaleza, a capital cearense, economicamente, é a quarta maior cidade do país, em área de $313,14 \mathrm{~km}^{2}$, a $16 \mathrm{~m}$ acima do nível do mar. Cidade turística, tem como sítio urbano a planície litorânea que se encontra com o sertão semiárido do Estado do Ceará. Assim, o clima quente subúmido, com temperatura média de $26^{\circ}$ a $28^{\circ} \mathrm{C}$, é atrativo ao turismo de sol e mar. É ocupada por 2.141.402 habitantes, totalmente urbanizada, embora com padrões e costumes do sertão pela periferia da capital. Atributos tropicais privilegiam o turismo de sol e praia o ano inteiro, águas do mar em temperaturas ideais para o banho. Os serviços são o principal arrecadador do 
ISSN: $1982-6125$

produto interno bruto (PIB) do Município, responsável por $79,66 \%$ do total (IPECE, 2009) e, entre eles, os turísticos que têm grande destaque.

Fortaleza é cidade litorânea, com fortes relações com o sertão, é que parte da população é de migrantes que buscam trabalho na capital ou fugindo de prolongadas estiagens do interior. O Ceará, durante anos, marcou-se pelos flagelos da seca. Na capital, por medidas de segurança, os retirantes alojavam-se em áreas distantes para evitar contato com as famílias tradicionais, o que resultou em focos de pobreza em áreas segregadas, longe dos olhos da elite e das autoridades.

A chuva leva o migrante de voltar ao sertão, embora muitos permaneçam na capital, adaptados ao novo estilo de vida. Entretanto, os que ficam, vão compor a massa de analfabetos sem qualificação profissional, em serviços mais pesados (SILVA, 2006, p.46). O distanciamento entre famílias tradicionais e migrantes sertanejos chega ao ponto de a presença de pobres, em praias e espaços públicos, ser tida como irresponsabilidade e falta de decência (JUCÁ, 2003, p.139). Assim, a relação de sertanejos com a capital mantém valores e costumes do sertão e, só a partir da década de 1980, Fortaleza volta-se para o mar pela valorização do litoral, com preferência de praias para lazer e espaços de turismo.

Fortaleza é conhecida como terra de belas praias, construída e reconstruída modernamente, mantendo intensa presença de coisas do sertão e do sertanejo. Hábitos e tradições do interior resistem ao tempo e guardam a memória do sertão, mesclam-se com a dinâmica urbana moderna da metrópole. Deste modo, o sertão vai até o mar e funde culturas, cria novos hábitos citadinos que passam a fazer parte do cotidiano da população do fortalezense. Explica Silva (2002, p.125) que:

Fortaleza é mescla de sertão molhado pelo mar com marcas de areia por onde passa. Sua brancura atravessa os tempos; a dos armazéns de algodão da segunda metade do século, agora retrasado, a das dunas brancas descobertas com a transposição do Jacarecanga, quando se expandiu oeste afora pelo Pirambu e Barra do Ceará. 
ISSN: $1982-6125$

A capital cearense, essencialmente litorânea, de coração sertanejo, privilegia elementos naturais que valorizam a paisagem e servem de atrativos turísticos. Os locais de ancoragem de embarcações embelezam a cidade e o litoral. Jangadas, barcos e suntuosos navios trafegam na costa configurando paisagem típica e estabelecendo relações comerciais que favorecem economias locais.

Fortaleza é pólo de atividades múltiplas, dinamizada por embates políticos entre esferas públicas e privadas. Complexos e contraditórios jogos de interesses sustentam políticas sobre o território, definindo uso e modo de ocupação do espaço urbano. A metrópole, pólo receptor de turismo, ostenta lugares especialmente estruturados para a moderna atividade e recebe visitantes de muitos países. Assim, Fortaleza, espaço de complexidade entre trabalho e lazer, formalidade e informalidade, riqueza e pobreza, apresenta realidade de acordo com conveniências. No jogo de interesses dos que brincam, querem lucros, vendem a força de trabalho, moram no lugar e dos que vêm em busca de lazer, há várias formas de conflitos. O papel do poder público é questionável quando se coloca como empreendedor, se diz acima das classes, mas se identifica com uma delas.

Fortaleza, de manifesta "litoralidade", é resultado de imagens criadas pelos meios de comunicação. A cidade do passado, associada à pobreza, dá lugar à metrópole do turismo de sol e praia, e a nova imagem repercute para o restante de cidades marítimas cearenses (DANTAS, 2002). A partir de então, a expansão do uso do litoral dá-se por meio do turismo que se apropria, por sua vez, do lazer e do ócio na lógica da reprodução do capital, alterando o quadro simbólico da cidade.

A metrópole marítima e sertaneja, embora frágil pelos contraditórios problemas socioespaciais, desponta no cenário nacional e internacional devido, sobretudo, ao trabalho realizado pelos media com a intenção de torná-la produto turístico internacional. Sol, praia, festas e humor, corpos bronzeados e saudáveis são largamente aproveitados na elaboração de apelos midiáticos para o marketing do turismo local. 


\section{Das Práticas do Lazer ao Lazer Mercadoria na Orla}

Lazer é necessidade básica e direito do cidadão e relaciona-se ao desenvolvimento da capacidade formativa e criativa, aprendizagem e ao crescimento humano. Assim, faz-se por todos independente de gênero, classe social e lugares. Fortaleza é tida como cidade de diversão, shows de humor, forró em plena segunda-feira, muitas vezes sem atingir a essência do lazer, pois ele vira lucro, consumo e espetáculo.

Os veículos de informação de massa ajudam a manter a visão de que o lazer está associado, simplesmente, às manifestações de massa ao ar livre com conteúdo recreativo (MARCELLINO, 2008, p.11) e oferecem satisfação imediata. Na visão de Dumazedier (1974, p.88) "toda atividade pode, pois, vir a ser um lazer", desde que realizada com prazer.

$\mathrm{Na}$ compreensão de lazer, Andrade (2001, p.110-116) propõe adjetivações da prática. Realiza-se em circunstâncias diferenciadas causando impactos sobre o trabalho, família e cultura, levando em conta as possibilidades do tempo disponível para a atividade. Para o autor, o lazer pode ser:

Espontâneo, que é aquele não previsto, programado, o mais conhecido e mais praticado, esporádico caracterizado por atividades específicas realizadas quando há disponibilidade de tempo, habitual o que se caracteriza pela diversão e relaxação depois do trabalho e o dos domingos, que não se caracteriza por algum diferencial, daí não existe dia tão semelhante ao outro como o domingo.

No senso comum, lazer está ligado a descanso e divertimento, sendo descanso restrito apenas à recuperação de forças laborais e divertimento ligado ao consumo às vezes alienado. $O$ desenvolvimento pessoal por meio de atividades socioeducativas, que engrandece o espírito humano, muitas vezes fica em segundo plano. Por isso é importante aprofundar o conhecimento de práticas do lazer para assumi-lo de maneira consciente. 
Lazer desmembrado de manifestações sagradas de sociedades précapitalistas tem dimensão individual, sem que esteja necessariamente ligado a outras motivações, embora mantenha estreita relação com calendários religiosos. Entretanto o lazer não pode ser reduzido a oposição ao trabalho, porque não sintetiza completamente o não-trabalho. Mesmo lazer em oposição ao trabalho, lembra Dumazedier (2004, p.31) existem outros tipos de trabalho não especificamente profissionais: domésticos, atividades de manutenção, alimentação, higiene pessoal e sono, atividades rituais, obrigações familiares, reuniões políticas e atividades ligadas a estudos. Deste modo, em certa medida, lazer se define como oposição também ao conjunto de necessidades e obrigações do cotidiano. Vale lembrar que o lazer não é praticado isoladamente, mas sim dialeticamente interligando atividades da vida cotidiana (DUMAZEDIER, 2004, p.32).

Espaços de lazer são lugares de manifestações culturais, práticas esportivas, criativas, lúdicas e de descanso, nas esferas públicas e privadas. São, sobretudo, espaços de educação não formal, latentes possibilidades de criação de vias de prática de capacidade criativa, como acontece nos espaços destinados a desfiles de escolas de samba no Rio de Janeiro e centros culturais. Entretanto, lazer como educação não é concepção explicita das políticas privadas, com foco no lucro.

Espaços públicos de lazer são da coletividade indistintamente. Em tese, diz-se lócus da prática democrática do descanso, da reposição de forças laborais, desenvolvimento cultural e diversão. Entretanto, transformam-se em espaços de consumo, privatizados por interesses individuais ou de determinada minoria, endossados pelo Estado, como acontece em orlas marítimas onde os empreendimentos de lazer, na instalação, desagregam comunidades, como no litoral do Ceará.

A realidade imposta às utopias revela o quanto os planejamentos estão distantes do que se produz no espaço factualmente. O "direito à cidade" de Lefebvre, de acordo com Rodrigues (2007), é o entendimento da "cidade como direito" dentro do complexo processo de urbanização, no qual argumenta: 
CORIOLANO, Luzia Neide; PARENTE, Karlos Markes. Espaços de reserva do capital na orla oeste de Fortaleza (Ceará, Brasil): demandas para Lazer e Turismo. Revista Brasileira de Pesquisa em Turismo. v.5, n.1, p.63-82, abr. 2011.

ISSN: $1982-6125$

A cidade como direto tem como base a vida real, o espaço concreto e o tempo presente. Ao contrário, no ideário da cidade ideal, o espaço e o tempo são abstrações. Reflete o pensamento de planejadores do Estado capitalista e do capital. Os problemas são considerados desvios do modelo, solucionáveis com novo tipo de planejamento e uso de novas tecnologias. Os avanços da tecnologia articulam formas e conteúdos da e na cidade, mas não "produzem" a cidade ideal, embora provoquem transformações na cidade real.

Na visão de Bobbio (1987, p.27), "[...] o direito privado toma a dianteira sobre o direito público e esta prevaricação da esfera inferior sobre a superior revelaria um processo em curso de degeneração do Estado". Daí o conflito no litoral de Fortaleza pela ocupação das barracas de praia, propriedades privadas em espaços públicos.

Fala-se de direito do homem ao lazer como necessidade básica, mais do que se fez para que direitos sejam reconhecidos e efetivamente postos em prática. A vida de consumo coopta o tempo do individuo para atividades produtivas de modo desproporcional, suprimindo-Ihe o tempo de lazer. Assim, apenas de modo retórico afirma-se que todos são iguais com direitos iguais, sobretudo de lazer e turismo, privilégio da sociedade da superprodução e superconsumo, marca dos tempos modernos.

O pragmatismo e a funcionalidade de ações políticas e econômicas neoliberais, bem como a permissividade do Estado resultam em nefastas consequências socioespaciais, incluem e excluem indivíduos de acordo com a renda. Os que gozavam do espaço público de lazer já não o fazem na qualidade de cidadãos, mas como consumidores de lazer coisificado, tido como espetáculo. Lazer, interpretado como alienação, ilusão de satisfação de necessidades do indivíduo, portanto criadas, manipuladas pelas forças econômicas da produção e consumo de massa (DUMAZEDIER, 1974), efetivamente cria barreiras ao entendimento de sua dimensão e, consequentemente, à viabilização de políticas de democratização dos espaços públicos da prática.

A reflexão provoca questionamentos acerca do papel dos espaços públicos de lazer nas grandes cidades, em especial, em Fortaleza. Quais os 
ISSN: $1982-6125$

critérios de seleção de lugares a serem estruturados ou reestruturados para lazer e turismo nas cidades? Que conflitos se estabelecem entre esferas públicas e privadas para uso e ocupação dos espaços? Como se configuram no espaço os resultados do conflito entre público e o privado? A discussão acerca de espaços públicos de lazer é cara à Geografia, que se ocupa de estudo do espaço físico, mas também nos campos filosófico e simbólico, levando em conta desdobramentos sociais, políticos e culturais que modelam o espaço geográfico.

O lazer constitui a essência da atividade turística e constitui importante eixo de pesquisa da Geografia contemporânea. Segundo Coriolano (1998, p.111), "as atividades lúdicas não são despojadas de significado sociogeográfico e assim interessam à Geografia".

Os espaços públicos de lazer e turismo são espaços políticos, construídos, reconstruídos, remodelados, retirados e recolocados, de acordo com interesses diversos. Os conflitos de interesses entre esferas públicas e privadas e, contraditoriamente, nem sempre as necessidades públicas são minimamente atendidas. Espaços de lazer são lugares simbólicos. Praças, jardins, parques e orla marítima carregam histórias típicas do lugar e expressam características próprias de determinado grupo social. As territorialidades reproduzem aspectos subjetivos, materializados pelo cotidiano do espaço vivido. Os delicados aspectos da relação de indivíduos com o espaço, quase sempre, são desconsiderados em projetos de intervenção públicos, resultando na desconfiguração e desarticulação do convívio social.

Mostra Giddens (1998, p.95) que as políticas públicas precisam levar em conta, sobretudo os espaços para a viabilização do desenvolvimento de comunidades sem, contudo, ignorar o contexto histórico do local, evitando desagregações socioespaciais de um grupo em detrimento do todo social:

As políticas de renovação comunitária não devem ignorar a esfera pública. Uma esfera pública aberta é tão importante em nível local quanto em nível nacional, e essa é uma das maneiras pelas quais a democratização se liga diretamente ao desenvolvimento comunitário. Sem isso, os esquemas de renovação comunitária ameaçam separar a 
CORIOLANO, Luzia Neide; PARENTE, Karlos Markes. Espaços de reserva do capital na orla oeste de Fortaleza (Ceará, Brasil): demandas para Lazer e Turismo. Revista Brasileira de Pesquisa em Turismo. v.5, n.1, p.63-82, abr. 2011.

ISSN: $1982-6125$

comunidade da sociedade mais ampla e são vulneráveis à corrupção. "Público" aqui inclui o espaço físico público. A degeneração de comunidades locais é comumente marcada não só por dilapidação geral, mas também pelo desaparecimento do espaço público seguro.

As desagregações socioespaciais de comunidades pobres, que habitualmente acontecem de forma unilateral e autoritária, atendem aos interesses da classe dominante e do Estado, politicamente comprometido. A realocação desagregadora, do ponto de vista do convívio social, fica evidente quando, na construção da Av. Presidente Castelo Branco, ou simplesmente Leste-Oeste, comunidades do Arraial Moura Brasil, Oitão Preto, Cinzas, Braga Torres e Soares Moreno, foram transferidas para outros locais como Jurema, em Caucaia, Conjunto Rondon e Vicente Pinzon. Assim, Fortaleza, no contexto histórico, é lugar de lazer e festa, práticas cooptadas pelo capital, em que empresários, especialmente dos setores imobiliário e turístico, loteiam a cidade. Para tanto, exigem-se constantes remoções de habitantes que, muitas vezes, ocupam área em processo de valorização imobiliária exigindo novas remoções.

As idéias de "cidade-festa", "festa-mercadoria" e "consumo cultural" (SERPA, 2007) ajudam o entendimento de transformações do espaço, por meio de políticas públicas e privadas, sobretudo de turismo que primam pelo consumo como motivação de intervenções. Em muitos casos, intervenções públicas priorizam conforto, segurança e lazer de turistas, ignorando residentes e suas condições de cidadania, desprestigiando os primeiros ocupantes dos espaços.

As transformações espaciais de lazer evidenciam-se pela ocupação e urbanização das praias por volta de 1970. Segundo Dantas (2002, p.62), a ocupação acontece do Farol do Mucuripe à Barra do Ceará, para veraneio, trabalho ou habitação. No contexto histórico, o Bairro do Poço das Dragas funcionou como elemento de atração de populações migrantes do sertão e formou bairros, comunidades e favelas: Pirambú, Arraial Moura Brasil, Jacarecanga e Carlito Pamplona, que perduram até hoje e estabelecem nova ordenação ao espaço urbano de Fortaleza. 
Levas de imigrantes abandonam os municípios de origem, no interior, vindos do sertão a procura de melhores condições de vida na Capital, fazendo crescer enormemente a população da cidade, sem condições suficientes para comportá-los. Enquanto as estiagens periódicas pressionam o êxodo dos moradores do campo para a capital, que se pretende turística, emerge no cenário do país como lugar de praias paradisíacas, de sol e humor.

Assim, parte significativa da população migrante estabelece-se inicialmente no lado oeste de Fortaleza, dada a proximidade com o pólo industrial da Av. Francisco Sá, com centro comercial e com a área portuária do Mucuripe. O pólo industrial destacava-se como importante parque têxtil e indústrias do setor metal-mecânico, instigando a imigração do interior do estado (VASCONCELOS, 2005, p.74). Assim, a orla oeste da cidade comporta, até hoje, população de baixa renda, migrante para Fortaleza, não apenas por problemas climáticos, mas também devido à estrutura fundiária concentradora do Ceará que repele o pequeno produtor agrícola e o proletariza. Essa porção da orla, pauperizada e carente de atenção por parte do Estado, segundo Araújo e Carleial (2003), indica que:

As rendas mais baixas dos chefes de domicílios, variam entre $R \$ 269,63$ a $R \$ 373,87$. É no setor oeste, que se vê a predominância. São bairros antigos e novos que se misturam, nesse traçado, acompanhando o litoral (Arraial Moura Brasil, Pirambu, Cristo Redentor, Barra do Ceará e Floresta).

Políticas públicas urbanas, na década de 1970, viabilizam importantes vias de acesso a Fortaleza: Avenidas Presidente Castelo Branco (Av. LesteOeste), José Bastos, Borges de Melo e Aguanambi, que favoreceram a mobilidade espacial, ligando áreas de poucas relações e promovendo maior circulação entre bairros, além disso, incentivando a especulação imobiliária.

Entretanto, intervenções do Estado acirram a segregação socioespacial, principalmente na orla oeste, quando são deslocadas populações em desarticulação do convívio de antigos moradores, impondo-lhes novo ritmo de vida. A integração de espaços pelo plano desenvolvimentista municipal da 
rede urbana representa importante transformação do espaço de Fortaleza, embora gere uma série de novos conflitos.

Reportagem do Jornal O Povo, de 04 de Abril de 2010, em Litoral Perdido, destaca sobre Fortaleza que: "[...] dos 43 quilômetros de orla, incluindo a orla do Rio Ceará são apenas 12 quilômetros de praia, o que representa 35\% do total". O Jornal enfatiza que $65 \%$ da orla da cidade não tem uso apropriado, estando o litoral escondido por construções irregulares, em dunas que viraram morros, emparedado por prédios, privatizado por hotéis e marinas. A reportagem destaca ainda que:

Nos 15 primeiros quilômetros, da Barra do Ceará até o kartódromo, a praia é o quintal de uma urbanização caótica. Quem passa pela Avenida Leste-Oeste nem enxerga o mar. O acesso é restrito aos moradores da área. A falta de segurança e a poluição da água afastam visitantes. Pouca gente já viu de perto a beleza do encontro do Rio Ceará com o mar e da praia linear que se estende a direita com surfistas, jangadas e coqueiros. Na sequência, a faixa de areia desapareceu em vários pontos. O mar se mostra, mas não é possível chegar nele. Até a Praia de Iracema, a praia praticamente não existe. As ondas quebram em paredões de pedra que controlam a erosão. A partir do aterro, entre as ruas Idelfonso Albano e Rui Barbosa, a praia volta a aparecer (O POVO, 04/04/ 2010).

A orla oeste de Fortaleza, desprestigiada, entra no circuito de reordenamento dos espaços da metrópole, vira mercadoria e vai sendo cooptada pela especulação, pela modernidade urbana.

\section{Conflitos de Interesses na Formação do Espaço da Orla Oeste}

A orla oeste registra conflitos socioespaciais entre esferas públicas e privadas na disputa de territórios. A remoção de moradores, na década de 1990, para a construção da Av. Leste Oeste e a posterior duplicação da pista geraram conflitos que marcaram a tensa relação entre poder público e residentes da área. 
ISSN: $1982-6125$

As ocupações registram histórias de disputas políticas entre gestores municipais e empresários, como na instalação do Marina Park Hotel, na década de 1990, com mudança de governo. Inaugurado em 1993, é o primeiro empreendimento privado do turismo globalizado a adentrar na porção oeste, desprestigiada e de ocupação marginal, fazendo contraponto à pobreza local. A disputa pela área é uma constante e o Jornal O Povo de 08 de julho de 2009, noticia que a gestão municipal tem intenção de construir um Centro de Convenções no Marina Park Hotel, o que significa disputa e ameaça ao hotel e mostra a "publicização" do privado e a privatização do público. A nota afirma que a gestão pública solicita à Secretaria de Infraestrutura (SEINF) laudo financeiro para desapropriação do hotel. A gestão municipal reforça o que já havia afirmado em entrevista ao mesmo jornal, no dia 28 de junho de 2009, que a localização do Marina Park Hotel seria perfeita para a implantação do novo empreendimento.

Os conflitos são de toda ordem, agora entre a atual gestão municipal e o Governo do Estado. Ambos disputam o litoral, especificamente no Bairro Serviluz, com diversos interesses, mostrando relações de força política. A orla é disputada para implantação de equipamentos turísticos e instalação de polêmico estaleiro. Assim, mais uma vez, governos estadual e municipal tencionam alocar equipamentos de grande impacto socioambiental para a porção menos cotada da orla marítima, por ser área ocupada por famílias pobres, vulneráveis a manobras políticas, o que o instiga disputas de forças políticas antagônicas.

Gestores de esferas municipal e estadual disputam a Praia Mansa, na orla oeste, local de interesses, por se ver potencial de lazer e turismo nessa praia (VASCONCELOS, 2005, p.45). Assim, a orla oeste de Fortaleza evidencia conflitos e contradições socioespaciais, destaque os da comunidade do Arraial Moura Brasil e Marina Park Hotel, ali estabelecido para lazer e turismo criando barreiras simbólicas entre os que ali são obrigadas a conviver.

Em contraposição ao Marina Park Hotel, têm-se espaços de lazer da população pobre, vizinha ao hotel, são as barracas de praia da Avenida Leste- 
CORIOLANO, Luzia Neide; PARENTE, Karlos Markes. Espaços de reserva do capital na orla oeste de Fortaleza (Ceará, Brasil): demandas para Lazer e Turismo. Revista Brasileira de Pesquisa em Turismo. v.5, n.1, p.63-82, abr. 2011.

ISSN: $1982-6125$

Oeste, alocadas na Praia Formosa, Bairro de Jacarecanga, com destaque para a "Barraca do Tio", que divide espaço com Marina Park Hotel.

O site do Marina Park hotel localiza o empreendimento na Praia de Iracema, embora esteja na Praia Formosa, conhecida como área de pobreza e prostituição, de lazer marginal, o que denota preconceito. O hotel é, assim, enclave socioespacial em região de pobreza e miséria. Inevitavelmente a elite entra em contato direto com a favela acentuando-se os conflitos sociais. A exploração capitalista avança sobre os espaços sacrificando a favela e os moradores que na concepção do estado, precisam ser removidos. A valorização do avanço forçosamente expulsa antigos habitantes por interferência de governos por meio de remoções seletivas. A remoção da população para assentamentos distantes é justificada por discursos sanitaristas, ambientais e de melhoria da qualidade de vida que, muitas vezes, não passam de retóricas. A realidade em que habitantes não dispõem das condições mínimas de vida, como pensar em política de lazer? O lazer para comunidades pobres é banalidade dispensável?

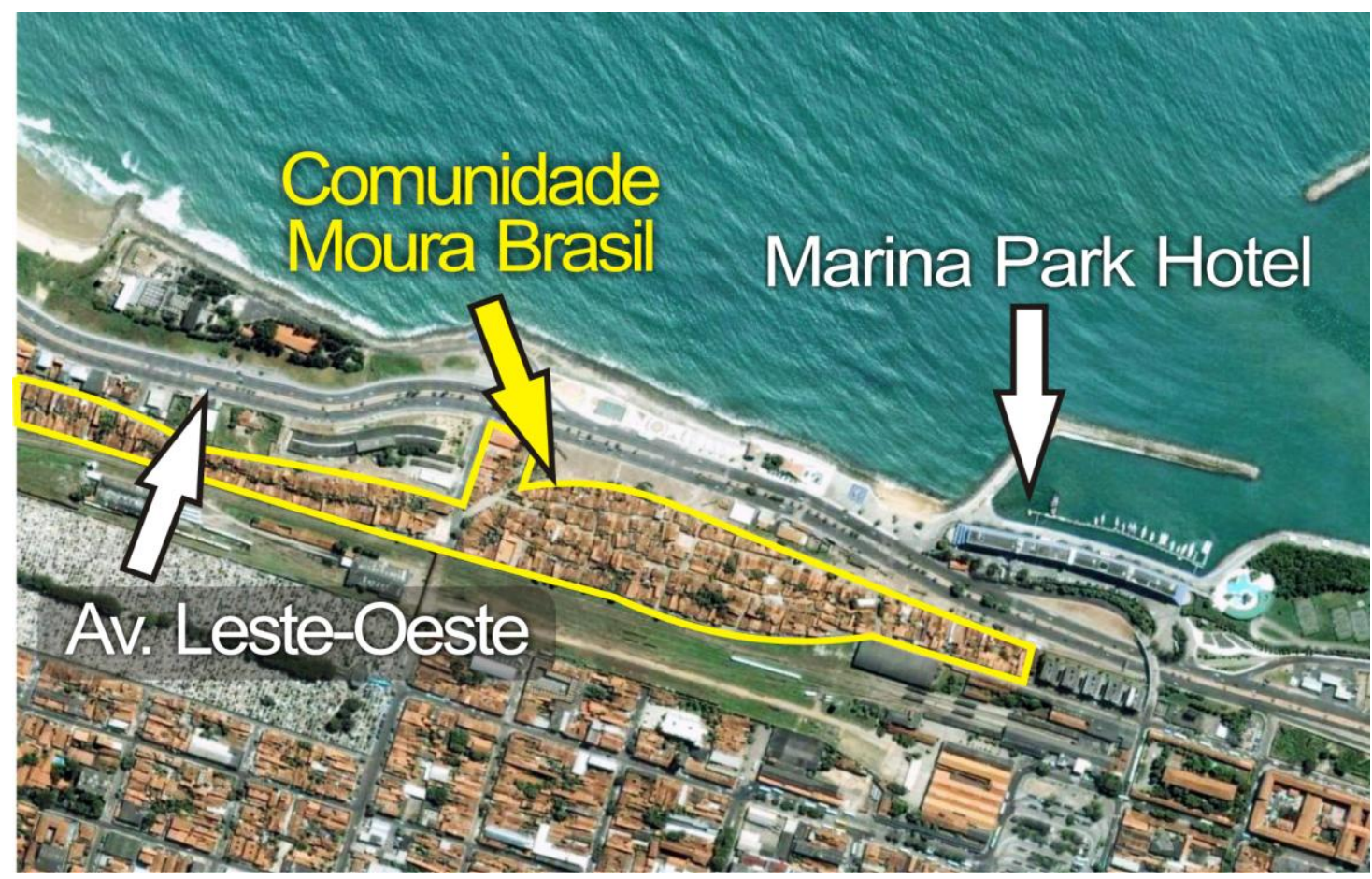

Figura 4 - Comunidade Arraial Moura Brasil e Marina Park Hotel

Fonte: Google Earth 2010 
Fortaleza vive a metáfora de Lefebvre (1999, p.26) "implosão-explosão", no processo fazer e refazer, construir e demolir envolvendo pessoas, atividades, riquezas, coisas, objetos, instrumentos, meios e idéias da realidade urbana. Explosão como projeção de fragmentos múltiplos e disjuntos com centros, periferias, subúrbios, residências secundárias e espaços de lazer e turismo. Lazer e turismo incluem-se em enorme concentração de força e poder, que explode conferindo à cidade novas produções espaciais, em especial no litoral. O modo de produção de espaços de lazer é indicativo de segregação socioespacial. A cidade é uma totalidade e a produção espacial é um fato político. Os espaços não são neutros: derivam de políticas repletas de intenções, públicas, privadas ou de iniciativa popular.

Eventos realizados pontualmente por gestores municipais, com vistas ao lazer da população, em área pública, são políticas paliativas, por não atenderem a população de modo sistemático e equânime, não fazerem parte da política pública sistematizada dando, muitas vezes, conotação eleitoreira. E o governo do Estado, por sua vez, preocupa-se, sobretudo com o apoio à alocação de megaempreendimentos: resorts, oferecendo infraestrutura às empresas de turismo, em lugares estrategicamente escolhidos, em especial orla marítima, interessado em divisas, mesmo que impactem ambientes e sacrifiquem comunidades locais. A orla marítima, reconhecidamente lugar de diversão, passa por constantes intervenções públicas que visam ao incremento da receita do município por meio do turismo, o que favorece a criação de grandes cadeias de resorts, hotéis e pousadas, atrativos de turistas.

Deste modo, o que se constrói não é a cidade desejada de todos, mas a imposta a todos, como diz o geógrafo Harvey (2009). O direito à cidade não é simplesmente ao que já existe, mas o direito de transformar a cidade em algo radicalmente diferente para residentes e visitantes.

Os meios de comunicação veiculam imagem de "Fortaleza Bela" confortável e acolhedora, que não corresponde a Fortaleza dos moradores de periferias e orla oeste. Argumentações tendenciosas de propagandas oficiais escamoteiam o emaranhado de problemas que se avolumam, agravando a 
ISSN: $1982-6125$

estabilidade socioeconômica e ambiental de Fortaleza. Há que se evidenciar o papel da gestão pública e políticas desiguais, geradoras de fronteiras simbólicas que dividem o espaço do turista e do citadino de baixa renda. Turistas desfrutam de espaços espetacularizados e confortáveis, criando-se "muros" que colocam moradores da orla oeste em desconforto calculado e representado por estatísticas da violência urbana. Assim, as dimensões do percebido e do vivido (LEFEBVRE, 1999) estão diretamente relacionadas à práxis como particularidades e diferenças no conjunto de atividades humanas, materiais ou imateriais, em condições indispensáveis à sociedade. No objeto estudado, as dimensões permeiam o processo, em curso, de urbanização de Fortaleza, revelando contradições e conflitos.

\section{Conclusões}

A saturação espacial pela intensa ocupação com equipamentos de lazer e turismo, bem como o valor de compra, venda e locações de imóveis, em partes nobres da orla, incitam a especulação imobiliária. Assim, partes menos cotadas, como Bairro Moura Brasil e mediações, pelo Centro em direção ao Bairro Barra do Ceará, recebem equipamentos de lazer e turismo de grande porte, embora ainda permaneçam carentes de equipamentos públicos de lazer.

O turismo, como vetor de desenvolvimento econômico comprometido com o grande capital, avança sobre áreas periféricas com apoio do Estado, sem levar em conta interesses públicos e impactos socioespaciais: remoção de famílias e consequente desmembramento das relações cotidianas de vizinhança.

Assim, a especulação de espaços menos cotados da Orla Oeste de Fortaleza acelera-se colocando espaços marginais no circuito da competitividade financeira entre proprietários fundiários, promotores imobiliários e empresários do turismo, que se choca com interesses das comunidades locais que resistem ou buscam alternativas. O Estado, enquanto 
ISSN: $1982-6125$

parte interessada, também especula e acirra conflitos de acordo com conveniências políticas, tendo em vista vantagens

As relações conflituosas entre esferas de governo, empresários e comunidades, tendo em vista uso e ocupação das terras desprestigiadas da orla, mostram que o espaço urbano litorâneo é parte de uma totalidade que passa por reestruturação visando expansão capitalista. Não é apenas lócus das ações humanas, é produto das relações sociais, sobretudo econômicas e políticas com relações de poder, ligado as relações mundiais tipicamente turísticas.

\section{Referências}

ANDRADE, J. V. de.. Lazer: princípios, tipos e formas na vida e no trabalho. Belo Horizonte: Autêntica, 2001.

ARAÚJO, A. M. M.; CARLEIAL, A. N. Opulência e miséria nos bairros de Fortaleza (Ceará/Brasil). Revista Electrónica de Geografía y Ciencias Sociales, ago. 2003, vol.VII, n.146.

BOBBIO, N.. Estado, governo, sociedade: por uma teoria geral da política. Rio de Janeiro: Paz e Terra, 1987.

CASTRO, I. E. de.. Geografia e política, território, escalas de ação e instituições. Rio de Janeiro: Bertrand Brasil, 2005.

CORIOLANO, L. N. M. T. (Org.).. Turismo com ética - Lazer e Turismo em busca de uma sociedade sustentável. Fortaleza: UECE, 1998, p.110-120.

CORIOLANO, L. N. M. T.. Do local ao global: o turismo litorâneo cearense. Campinas: Papirus, 1998.

DANTAS, E. W. C.. Mar à vista: estudo da maritimidade em Fortaleza. Fortaleza, Museu do Ceará, Secretaria da Cultura e Desporto do Ceará, 2002.

DUMAZEDIER, J.. Lazer e cultura Popular. São Paulo: Perspectiva, 2004.

DUMAZEDIER, J.. Sociologia empírica do Lazer. São Paulo: Perspectiva, 1974.

GIDDENS, A. A terceira via: reflexões sobre o impasse político atual e o futuro da social-democracia. Rio de Janeiro: Record, 1999.

HARVEY, D.. A condição pós-moderna. São Paulo: Edições Loyola, 1989.

IPECE. Perfil básico municipal (PBM). Fortaleza: 2009.

JUCÁ, G. N. M.. Verso e reverso do perfil urbano de Fortaleza (1945-1960). São Paulo: Annablume, 2003.

LEFEBVRE, H.. A revolução urbana. Belo Horizonte: Ed. UFMG, 1999.

O POVO. "O que resta do litoral de Fortaleza". 04 abr. 2010. Cobertura Especial: Litoral Perdido

PONTE, S. R.. Fortaleza Belle Époque: reformas urbanas e controle social (1860-1930). Fortaleza: Edições Demócrito Rocha, 2001. 
ISSN: $1982-6125$

RODRIGUES, A. M.. Problemas del mundo actual, soluciones y alternativas desde la geografía y las ciencias sociales. IX Colóquio Internacional de Geocrítica, Universidade Federal do Rio Grande do Sul, Porto Alegre, 28 de maio - 10 de junho de 2007.

SERPA, A.. O espaço público na cidade contemporânea. São Paulo: Contexto, 2007.

SILVA, J. B. da. Fortaleza Mar e Sertão; In CHAVES, G. (Org). Ceará de corpo e alma: um olhar contemporâneo de 53 autores sobre a terra da luz. Rio de Janeiro: Relume Dumará/Fortaleza: Instituto do Ceará (Histórico, Geográfico e Antropológico), 2002, p.123-129.

VASCONCELOS, F. P.. Gestão integrada da zona costeira: ocupação antrópica desordenada, erosão, assoreamento e poluição ambiental do litoral. Fortaleza: Papirus, 2005.

VILLAÇA, F.. Espaço intra-urbano no Brasil. São Paulo: Studio Nobel, 2001.

Artigo recebido em novembro de 2010.

Aprovado para publicação em março de 2011. 